Supporting Information for

\title{
Kinetic Insights into the Iron-Based \\ Electrochemically Mediated Atom Transfer Radical \\ Polymerization of Methyl Methacrylate
}

\author{
Jun-Kang Guo, Yin-Ning Zhou, Zheng-Hong Luo* \\ Department of Chemical Engineering, School of Chemistry and Chemical \\ Engineering, Shanghai Jiao Tong University, Shanghai 200240, P. R. China
}


Table S1. Kinetic Equations for All Species in Iron-Based eATRP

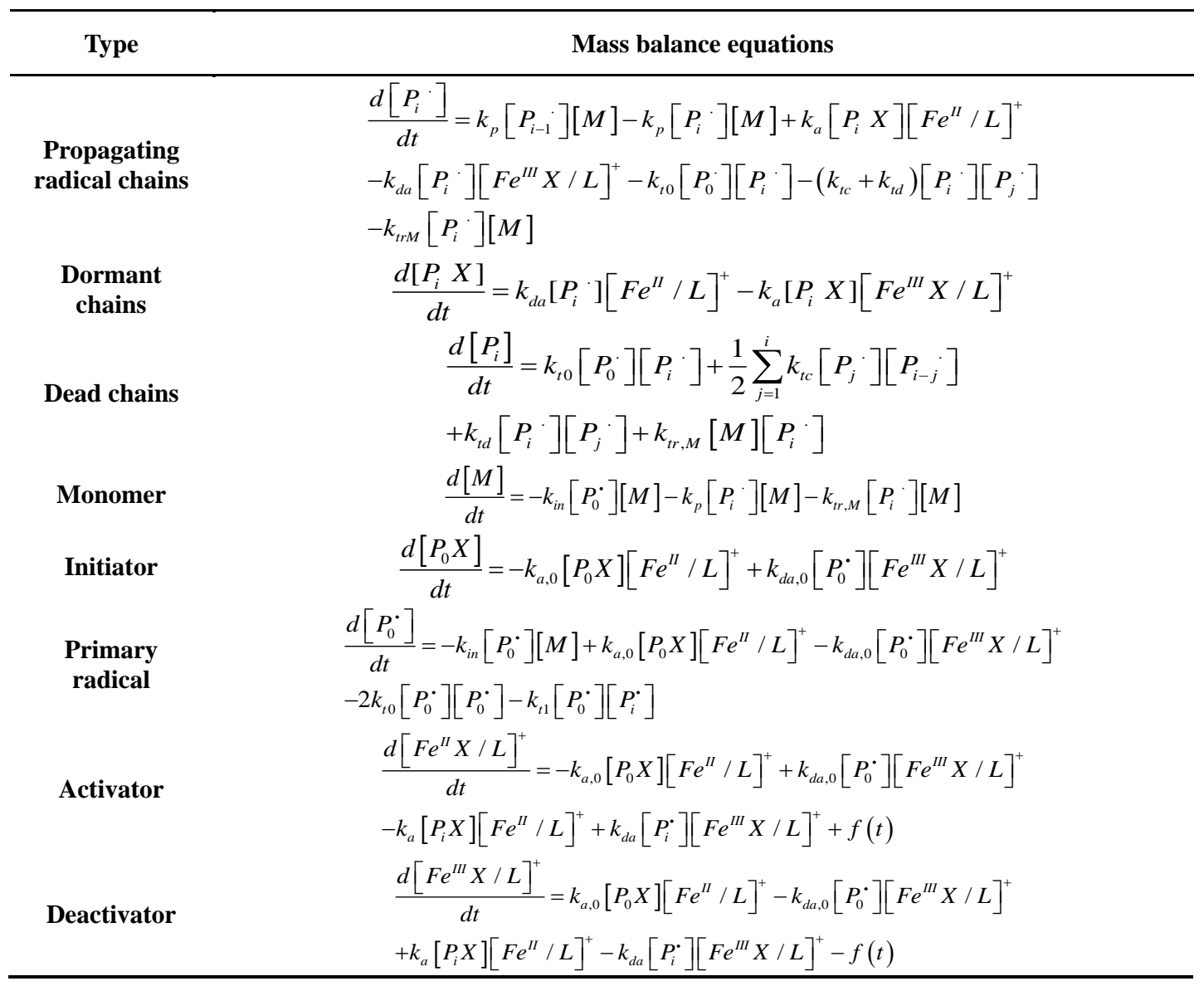

Table S2. Definition of Various Chain Moments

\begin{tabular}{cc}
\hline Type of chains & Definition of the moments \\
\hline Propagating radical & $\mu^{m}=\sum_{i=1}^{\infty} r^{m}\left[P_{i}\right]$ \\
Dormant & $\lambda^{m}=\sum_{i=1}^{\infty} r^{m}\left[P_{i} X\right]$ \\
Dead & $\tau^{m}=\sum_{i=1}^{\infty} r^{m}\left[P_{i}\right]$ \\
\hline
\end{tabular}


Table S3. Differential Moment Equations for The Species in eATRP

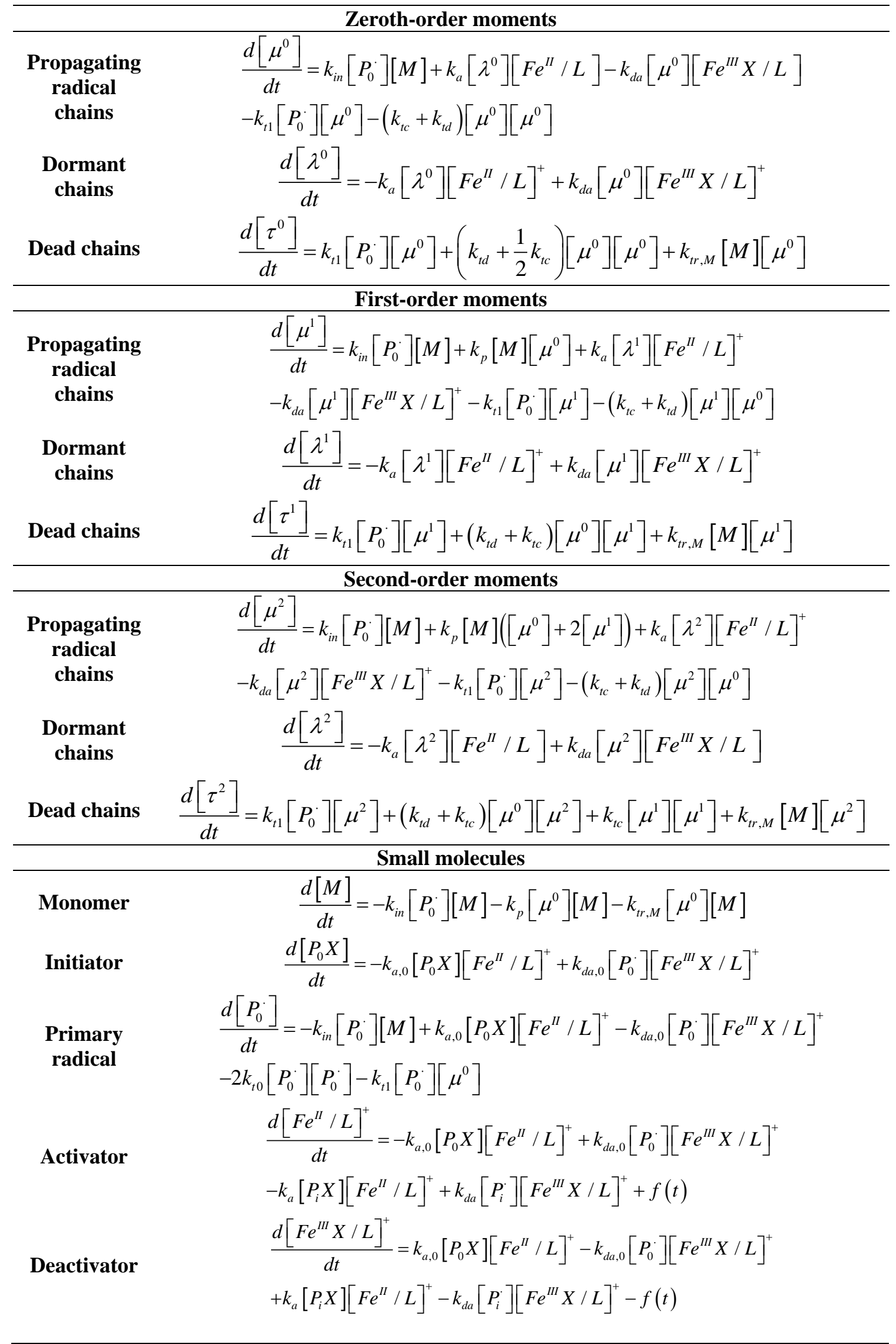

